\title{
Timing of Supplemental Feeding for Tilapia Production
}

\author{
JAMES S. Diana ${ }^{1}$ \\ School of Natural Resources, University of Michigan, \\ Ann Arbor, Michigan 48109-1115 USA \\ C. KWEI LiN AND YANG YI \\ Asian Institute of Technology, G.P.O. Box 2754, \\ Bangkok 10501 Thailand
}

\begin{abstract}
The staged addition of feed to fertilized fish ponds was evaluated by adding fertilizers to 15 ponds stocked with Nile tilapia Oreochromis niloticus, then adding feed at half ad libitum rates once fish in the ponds reached a target weight. Each pond was stocked with 750 fish (3 fish $/ \mathrm{m}^{2}$ ), and each treatment included three ponds with first feeding at (a) $50 \mathrm{~g}$, (b) $100 \mathrm{~g}$, (c) $150 \mathrm{~g}$, (d) $200 \mathrm{~g}$, and (e) $250 \mathrm{~g}$. Ponds in Thailand (at the Ayutthaya Freshwater Fisheries Station, Royal Thai Department of Fisheries) were maintained for 236-328 d until the fish reached $500 \mathrm{~g}$.

Growth was similar for all treatments under fertilizer alone $(1.17 \mathrm{~g} / \mathrm{d})$ and was also similar when feed was applied $(3.1 \mathrm{~g} / \mathrm{d})$. Feed application rates averaged $1.17 \% \mathrm{BW} / \mathrm{d}$, indicating substantial use of natural food. Pond water quality did not deteriorate under supplemental feeding. Feed conversion rates averaged 1.03. Multiple regression indicated that $73.8 \%$ of the variance in growth was explained by design variables (feed input and days), while $86.2 \%$ of the variance in growth was explained by adding dissolved oxygen content and alkalinity into the equation.

The most efficient system was to grow fish to $100-150 \mathrm{~g}$ with fertilizers alone, then add feed. First adding feed (at $50 \%$ ad libitum) once fish reached $100 \mathrm{~g}$ produced the highest predicted annual revenues $(\$ 6,164$ per hectare). Results of this experiment indicated that either critical standing crop occurred early (before the first fish sample) or did not occur at all in these ponds.
\end{abstract}

The culture of Nile tilapia Oreochromis niloticus is commonly done worldwide in semi-intensive systems with fertilization. Additionally, feed may be provided for part or all of a grow-out to increase carrying capacity and growth of fish. Earlier experiments indicated that supplemental feeding in fertilized ponds resulted in significantly higher growth rates and greater yields than fertilization alone (Green 1992; Diana et al. 1994). Diana et al. (1994) determined that feeding rates of 50 to $100 \%$ ad libitum, combined with fertilization under optimal levels (Knud-Hansen et al. 1991), resulted in similar growth rates and yields. Fish in such systems grew to near $500 \mathrm{~g}$ in $160 \mathrm{~d}$,

I Corresponding author. and yields approached $10,000 \mathrm{~kg} / \mathrm{ha}$. Since larger fish often fetch a higher market price, these yields may even be more valuable than increased biomass alone. Early growth of tilapia differed significantly in these feeding treatments, and it was unclear whether critical standing crop was ever reached, or whether it occurred in the first month of grow-out.

Hepher (1978) proposed the concepts of critical standing crop (CSC) and carrying capacity as mechanisms to regulate and understand fish production in aquaculture ponds. According to his data from carp ponds, fish growth was similar in early grow-out stages regardless of inputs. Once the fish grew and reached critical standing crop, growth declined. This growth could 
then be stimulated by increasing inputs, such as moving from fertilization alone to supplemental feeding. Data collected so far are unclear as to the existence and timing of this decline in growth for tilapia (Zonneveld and Fadholi 1991; Green 1992; Diana et al. 1994). The timing and size of fish at CSC is important if management intensity is to be regulated by this concept (Hepher 1978).

The purpose of this experiment was to determine the optimal timing of supplementally feeding Nile tilapia in fertilized ponds, both as a technique to produce larger fish than fertilization alone and also as one means to further determine relationships between growth and critical standing crop. In particular, we hoped to determine appropriate times for initial application of supplemental feed in fertilized ponds.

\section{Materials and Methods}

Data for this study were collected at the Ayutthaya Freshwater Fisheries Station located at Bang Sai $\left(14^{\circ} 45^{\prime} \mathrm{N}, 100^{\circ} 32^{\prime} \mathrm{E}\right)$, approximately $60 \mathrm{~km}$ northwest of Bangkok, Thailand. Fifteen earthen ponds used in the experiments were $250 \mathrm{~m}^{2}$ in surface area, and normally filled to a maximum depth of $1.0 \mathrm{~m}$ (mean depth $0.88 \mathrm{~m}$ ). All ponds were fertilized weekly with $1.5 \mathrm{~kg}$ urea (60 $\mathrm{kg} / \mathrm{ha}$ ) and $0.85 \mathrm{~kg}$ triple super phosphate (34 kg/ha).

Five treatments were used to estimate optimal timing for first feed application. In all treatments, sex-reversed males were reared early on fertilizer alone at densities of 3 fish $/ \mathrm{m}^{2}$. They were ultimately reared until they reached about $500 \mathrm{~g}$. Use of supplemental feed for each treatment was initiated when fish first reached a target weight. The five treatments varied in the size of fish at first feeding, with first feeding occurring when fish reached a mean weight of (a) 50 $\mathrm{g}$, (b) $100 \mathrm{~g}$, (c) $150 \mathrm{~g}$, (d) $200 \mathrm{~g}$, and (e) $250 \mathrm{~g}$. These treatments resulted in different timing of first feeding and harvest for each treatment.

Each feeding treatment was done in trip- licate. Sex-reversed Nile tilapia were stocked on 15 January 1993. Stocking density was $3 \mathrm{fish} / \mathrm{m}^{2}$ and size at stocking averaged $15 \mathrm{~g}$. Every two weeks, 40 fish from each pond were sampled, and individual weight (to $1 \mathrm{~g}$ ), as well as length (to $1 \mathrm{~mm}$ ) were determined. Growth rate was calculated as the increase in weight per day between sampling periods. Once the average size of fish in a treatment approximated the target weight, feeding commenced. Floating feed ( $30 \%$ crude protein) was provided to each pond in a treatment. Ad libitum feeding rates were determined for each pond by measuring the total amount of feed eaten from $0700-0900 \mathrm{~h}$ and from $1500-1700 \mathrm{~h}$ every Monday. Feed was applied sequentially to each pond until all feed was eaten. Feed application rates (50\% ad libitum) were then calculated for each treatment, and this rate was applied from Tuesday through Sunday. Feeding was continued until the mean weight of fish in at least two ponds in each treatment was projected to exceed $500 \mathrm{~g}$, then the ponds for that treatment were harvested.

Tilapia reproduction occurred to a limited extent in all ponds. Biomass of fry produced averaged $15.9 \mathrm{~kg} /$ pond, with a maximum of $34.3 \mathrm{~kg}$. This was less than $10 \%$ of the adult fish biomass in any pond. Fry seined during biweekly sampling were discarded, and fry weights were not included in tilapia growth or yield calculations.

Meteorological data, including solar radiation, rainfall, and wind speed were collected daily. Pond water column samples were analyzed biweekly for ammonia, nitrate-nitrite, orthophosphate, total phosphorus, alkalinity, pH, Secchi-disk depth, and chlorophyll $a$ content using standard methods (APHA 1980; Egna et al. 1987; Diana et al. 1991b). Dissolved oxygen and temperature were measured at the top, middle, and bottom of the water column in early morning. In addition, vertical distribution of dissolved oxygen, temperature, $\mathrm{pH}$, alkalinity, and ammonia was determined at $0600,0900,1400,1600,1800,2300$, and 
$0600 \mathrm{~h}$ in each pond. These diurnal analyses were repeated monthly on water from the top $(25 \mathrm{~cm})$, middle, and $25 \mathrm{~cm}$ above the bottom of the water column. Maximum temperature and oxygen differentials were calculated as the difference between top and bottom measurements at $1600 \mathrm{~h}$.

Primary production was determined by oxygen changes in the ponds, using methods described by Hall and Moll (1975) and Piedrahita (1988). Daily oxygen production was corrected for diffusion and nocturnal respiration. Gross primary production (oxygen basis) was then converted to carbon synthesis by relative molecular weights.

Statistical analyses were conducted using SYSTAT (Wilkinson 1990). Overall growth $(\mathrm{g} / \mathrm{d})$, net yield $(\mathrm{kg})$, and daily yield $(\mathrm{kg} / \mathrm{d})$ were calculated for each pond. Feed conversion rates were calculated as the increase in fish biomass divided by feed applied over the entire experiment. Average overall values for physical and chemical parameters, total days of culture, total days of feeding, total food input, and total fertilizer input were also calculated. Analysis of variance was used to test for treatment differences in means; while analysis of covariance was used to test treatment differences in growth rates (slope of curve between mean size and time). Multiple regressions between growth rate and design variables (feed input, days of culture) were done to test main treatment effects. Because many of the chemical variables were interrelated, residuals of the above regression were correlated to each physical or chemical variable. Significantly correlated variables were then examined for autocorrelation, and acceptable variables input to the multiple regression to evaluate determinants of fish growth. Variables were included in the regression if $P<0.10$. Treatment effects on fish or chemical variables were tested with the biweekly data set by ANOVA and Tukey's multiple range test. Differences were considered significant at an alpha of 0.05 .

Preliminary economic evaluations of each grow-out were done using Pond 3.0
(Copyrighted to Oregon State University, Bolte et al. 1996). Facility costs and labor were not included in the analysis, because the intent was only to compare relative differences in efficiency among treatments, and we assumed the previous costs would be similar for all treatments. Local market prices were used to estimate costs and income, which were all converted into U.S. dollars. Feed prices were set at $\$ 0.50 / \mathrm{kg}$, urea and triple super phosphate combined at $\$ 0.284 / \mathrm{kg}$, and sex-reversed fry at $\$ 0.009$ each. Market value of Nile tilapia varied with size: fish from $100-300 \mathrm{~g}$ sell at $\$ 0.48 / \mathrm{kg}$, from $300-499 \mathrm{~g}$ at $\$ 0.60 / \mathrm{kg}$, and above $500 \mathrm{~g}$ at $\$ 0.80 / \mathrm{kg}$.

\section{Results}

Initial trajectories for growth rate were similar among all treatments. Once feeding commenced, growth rate of fish in that treatment increased dramatically (Fig. 1). All treatments showed parallel rates of growth under fertilization conditions, and also parallel rates of growth under feeding conditions.

The timing of harvest was problematic among treatments. We intended to project the date at which mean weight of at least two ponds reached $500 \mathrm{~g}$, then harvest. However, we inadvertently let fish in growout treatments $A$ through D continue for too long. Treatment A took $236 \mathrm{~d}$ to harvest, while it could have been harvested in 196 d. Comparable actual and possible dates were 236 (210) for treatment B, 265 (224) for treatment $C$, and 305 (266) for treatment D. Since growth rate continued linearly throughout the fed portion of the grow-out, this should not have affected annual yield estimation much.

For various treatments, first feeding occurred between one and eight months after stocking (Fig. 1). While fish were stocked at similar weights (Table 1), their sizes diverged early after initiation of supplemental feeding, and overall weight and growth rate varied with treatment (Tables 2, 3). First feeding occurred on days $38,80,153,178$, 


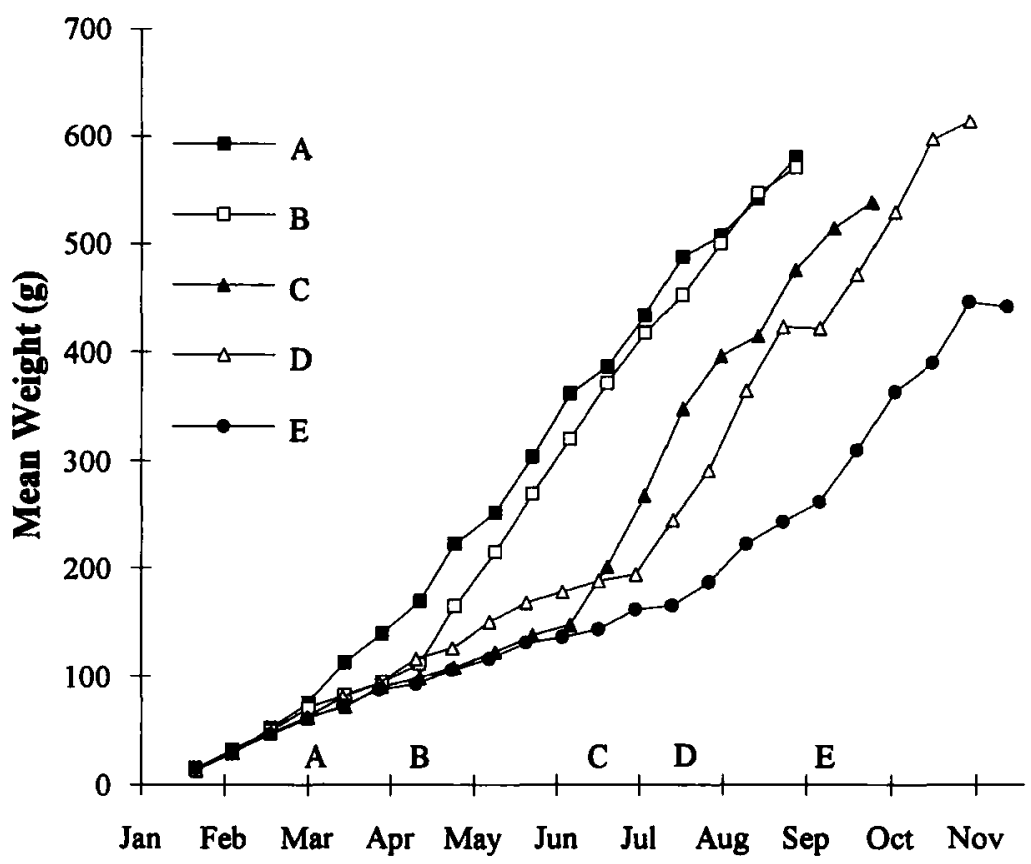

FIGURE 1. Weekly mean weight for tilapia in each treatment. Treatments were first feeding at: A) $50 \mathrm{~g}, \mathrm{~B}) 100$ $\mathrm{g}$, C) $150 \mathrm{~g}, \mathrm{D}) 200 \mathrm{~g}$, and E) $250 \mathrm{~g}$. The letters $A$ to $E$ on the $x$ axis indicate dates when supplemental feeding was initiated for each treatment.

and 234 in treatments A-E, respectively. Growth rates were significantly different during the feeding stage $(3.10 \mathrm{~g} / \mathrm{d})$ and the fertilizer-only stage $(1.17 \mathrm{~g} / \mathrm{d})$ of the experiments, but were not significantly different among treatments within a stage. The growth trajectories also did not differ significantly among treatments in the fed or unfed stages (ANCOVA). Ad libitum feeding rates varied from 0.07 to $3.71 \%$ body weight per day (\%BW/d), and averaged $1.17 \% \mathrm{BW} / \mathrm{d}$ (Fig. 2). There were no significant differences among treatments in ad libitum feeding rates. Similarly, feed conversion rates averaged 1.03 , and were not significantly different among treatments.

Fish parameters were sometimes correlated with treatments. Survival and biomass at harvest were not significantly different among treatments (ANOVA). One pond (D3) had extremely low survival and biomass at harvest (Table 2). Both overall growth and yield rates $(\mathrm{g} / \mathrm{d}$ and $\mathrm{kg} / \mathrm{d}$, respectively) were significantly higher in the two earliest fed treatments than in the latest fed treatment.

Multiple regression analyses indicated that growth rate $(\mathrm{g} / \mathrm{d})$ was significantly correlated with the main experimental variables of days and input of feed (Table 4). The regression explained $73.8 \%$ of the variation in growth rate. Residuals of the multiple regression for growth rate were significantly correlated with alkalinity $(r=$ $0.672, P=0.006$ ), chlorophyll $a$ content ( $r$ $=0.734, P=0.002$ ), gross primary productivity ( $r=0.700, P=0.004$ ), total inorganic nitrogen $(r=-0.699, P=0.004)$ and dissolved oxygen $(r=0.628, P=$ 0.012 ). Significant positive correlations were found between alkalinity and chlorophyll $a$, alkalinity and total inorganic nitrogen, alkalinity and gross primary productivity, chlorophyll $a$ and gross primary productivity, and dissolved oxygen and gross primary productivity. Significant negative correlations were found between alkalinity and total inorganic nitrogen, chlorophyll $a$ 
TABLE 1. Weights (mean and SD) at stocking, first feeding, and harvest in each experimental pond, as well as the total amount of feed added to each pond.

\begin{tabular}{|c|c|c|c|c|c|c|c|}
\hline \multirow[b]{3}{*}{ Pond } & \multicolumn{6}{|c|}{ Weight (g) } & \multirow{3}{*}{$\begin{array}{c}\text { Feed } \\
\text { added } \\
(\mathrm{kg} / \mathrm{ha})\end{array}$} \\
\hline & \multicolumn{2}{|c|}{ Stocking } & \multicolumn{2}{|c|}{$\begin{array}{c}\text { First } \\
\text { feeding }\end{array}$} & \multicolumn{2}{|c|}{ Harvest } & \\
\hline & Mean & SD & Mean & SD & Mean & SD & \\
\hline Al & 14.0 & 5.9 & 64 & 18.3 & 547 & 86.4 & 15,923 \\
\hline $\mathrm{A} 2$ & 14.9 & 5.0 & 42 & 12.7 & 657 & 120.0 & 18,352 \\
\hline A3 & 15.1 & 5.1 & 50 & 10.6 & 574 & 72.8 & 18,268 \\
\hline A & 14.7 & & 52 & & 593 & & 17,514 \\
\hline Bl & 15.7 & 4.6 & 99 & 20.8 & 686 & 107.7 & 15,190 \\
\hline $\mathrm{B} 2$ & 15.3 & 4.6 & 140 & 21.6 & 523 & 88.1 & 13,807 \\
\hline B3 & 15.2 & 3.6 & 94 & 19.5 & 579 & 109.0 & 13,989 \\
\hline B & 15.4 & & 111 & & 596 & & 14,329 \\
\hline $\mathrm{Cl}$ & 15.9 & 4.5 & 140 & 20.1 & 534 & 96.1 & 13,403 \\
\hline $\mathrm{C} 2$ & 15.1 & 4.5 & 179 & 24.0 & 606 & 111.7 & 12,782 \\
\hline $\mathrm{C} 3$ & 14.3 & 6.9 & 124 & 17.1 & 462 & 91.7 & 13,276 \\
\hline C & 15.1 & & 148 & & 534 & & 13,154 \\
\hline D1 & 15.9 & 3.9 & 161 & 26.0 & 584 & 100.4 & 15,387 \\
\hline D2 & 14.0 & 5.0 & 202 & 24.3 & 640 & 119.7 & 16,939 \\
\hline D3 & 14.0 & 3.8 & 219 & 39.4 & 657 & 114.3 & 15,407 \\
\hline D & 14.6 & & 194 & & 627 & & 15,911 \\
\hline El & 14.8 & 5.1 & 273 & 58.3 & 502 & 95.0 & 11,474 \\
\hline E2 & 15.9 & 4.8 & 269 & 38.9 & 553 & 103.3 & 11,373 \\
\hline E3 & 14.0 & 4.7 & 187 & 34.1 & 410 & 69.7 & 10,885 \\
\hline $\mathbf{E}$ & 14.9 & & 243 & & 488 & & 11,244 \\
\hline
\end{tabular}

and total inorganic nitrogen, and dissolved oxygen and total inorganic nitrogen. Because of the strengths of correlations and the nature of the variables, the final regression was chosen utilizing alkalinity and dissolved oxygen, as well as the original design variables. This final regression with fish growth included feeding rate, dissolved oxygen and alkalinity and explained $86.2 \%$ of the variance in growth (Table 4).

Some chemical parameters varied among treatments in this experiment. Chlorophyll $a$ content and alkalinity both differed significantly among treatments (ANOVA), with the latest fed treatment $(E)$ being significantly lower in both values than the next to last fed treatment (D). Also, $\mathrm{pH}$ differed significantly, with the three earliest fed treatments having lower $\mathrm{pH}$ values than the last two fed treatments. Combined inputs of fertilizer and feed generally resulted in no change in water quality compared to fertil-
TABLE 2. The biomass, number, and mean size of tilapia harvested from each pond.

\begin{tabular}{lccc}
\hline Pond & Biomass (kg) & Number & Size $(\mathrm{g})$ \\
\hline A1 & 334.0 & 611 & 547 \\
A2 & 427.4 & 651 & 657 \\
A3 & 393.3 & 685 & 574 \\
A & 384.9 & 649 & 593 \\
B1 & 455.7 & 664 & 686 \\
B2 & 342.7 & 655 & 523 \\
B3 & 354.4 & 612 & 579 \\
B & 384.3 & 644 & 596 \\
C1 & 319.3 & 598 & 534 \\
C2 & 371.2 & 613 & 606 \\
C3 & 316.0 & 684 & 462 \\
C & 353.3 & 632 & 534 \\
D1 & 373.3 & 639 & 584 \\
D2 & 422.7 & 660 & 640 \\
D3 & 223.9 & 341 & 657 \\
D & 340.0 & 547 & 627 \\
E1 & 333.5 & 664 & 502 \\
E2 & 377.2 & 682 & 553 \\
E3 & 260.8 & 636 & 410 \\
E & 323.8 & 661 & 488 \\
\hline
\end{tabular}

TABLE 3. Growth (g/d), survival (\%), change in biomass ( $k g / h a)$, and annual yield ( $k g / h a$ per $y r)$ for tilapia from each pond.

\begin{tabular}{|c|c|c|c|c|c|c|}
\hline \multirow[b]{2}{*}{ Pond } & \multicolumn{3}{|c|}{ Growth } & \multirow[b]{2}{*}{$\begin{array}{l}\text { Sur- } \\
\text { vival }\end{array}$} & \multirow[b]{2}{*}{$\begin{array}{c}\text { Change } \\
\text { in bio- } \\
\text { mass }\end{array}$} & \multirow[b]{2}{*}{$\begin{array}{c}\text { Annual } \\
\text { yield }\end{array}$} \\
\hline & $\begin{array}{l}\text { Pre- } \\
\text { feed- } \\
\text { ing }\end{array}$ & $\begin{array}{l}\text { Dur- } \\
\text { ing } \\
\text { feed- } \\
\text { ing }\end{array}$ & $\begin{array}{c}\text { Over- } \\
\text { all }\end{array}$ & & & \\
\hline Al & 1.76 & 2.63 & 2.32 & 81.5 & 12,940 & 20,535 \\
\hline A2 & 1.14 & 2.99 & 2.79 & 86.8 & 16,648 & 26,420 \\
\hline A3 & 1.43 & 2.72 & 2.43 & 91.3 & 15,280 & 24,249 \\
\hline B1 & 1.00 & 3.84 & 2.92 & 88.5 & 17,756 & 28,178 \\
\hline B2 & 1.49 & 2.78 & 2.21 & 87.3 & 13,248 & 21,024 \\
\hline B3 & 0.95 & 3.24 & 2.45 & 81.6 & 13,720 & 21,773 \\
\hline $\mathrm{Cl}$ & 1.18 & 3.51 & 2.00 & 79.7 & 12,296 & 17,328 \\
\hline $\mathrm{C} 2$ & 1.43 & 4.16 & 2.28 & 81.7 & 14,396 & 20,288 \\
\hline C3 & 1.01 & 2.78 & 1.73 & 91.2 & 12,212 & 17,210 \\
\hline D1 & 1.10 & 3.17 & 1.90 & 85.2 & 14,456 & 17,647 \\
\hline D2 & 1.24 & 3.36 & 2.10 & 88.0 & 16,488 & 20,127 \\
\hline D3 & 1.45 & 3.34 & 2.15 & 45.5 & 8,536 & 10,420 \\
\hline $\mathbf{E} 1$ & 1.15 & 2.70 & 1.51 & 88.5 & 12,896 & 14.618 \\
\hline $\mathrm{E} 2$ & 1.17 & 3.02 & 1.67 & 90.9 & 14,612 & 16,563 \\
\hline E3 & 0.78 & 2.56 & 1.23 & 84.8 & 10,012 & 11,349 \\
\hline
\end{tabular}




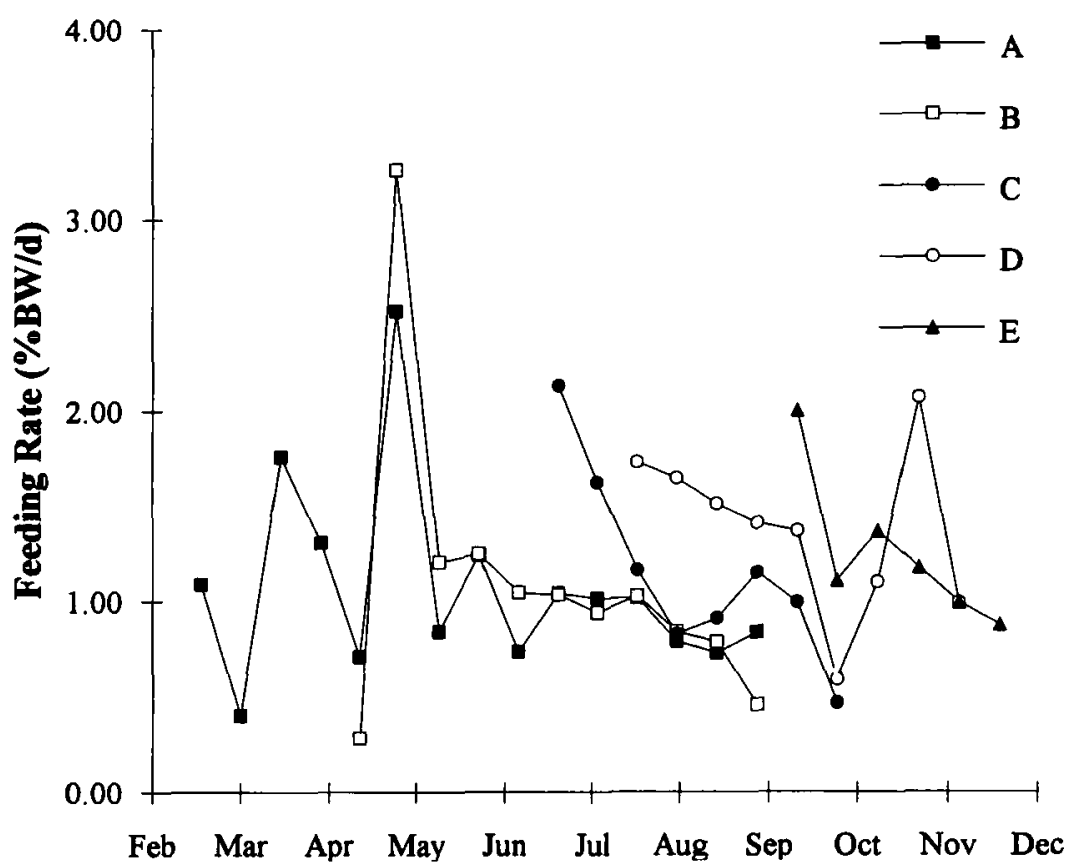

FIGURE 2. Mean feeding rates $(\% B W / d)$ for tilapia in each treatment.

ization alone, in spite of higher loading rates (Table 5). These feeding rates averaged $116 \mathrm{~kg} / \mathrm{ha}$ per $\mathrm{d}$ (minimum 1.6 , maximum 390) during the feeding period. Dissolved oxygen, ammonia, $\mathrm{pH}$, total dissolved phosphorus, total inorganic nitrogen and Secchi disk depth showed no significant differences within a treatment before or after feeding, although they did vary sporadically over time. The only variables showing such an effect were related to strat-

TABLE 4. Results of multiple regression analyses for fish growth $(\mathrm{g} / \mathrm{d})$.

\begin{tabular}{lrc}
\hline \multicolumn{1}{c}{ Variable } & Coefficient & $P$ \\
\hline \multicolumn{1}{c}{ Main effects- $R^{2}=$} & $0.738, P=0.001$ \\
Constant & 2.799 & 0.008 \\
Feed input & 0.000 & 0.028 \\
Days & -0.006 & 0.009 \\
\multicolumn{1}{c}{ Overall effects- $R^{2}=$} & $0.862, P=0.001$ \\
Constant & 179.549 & 0.124 \\
Feed input & 0.001 & 0.002 \\
Days & 0.278 & 0.320 \\
Dissolved oxygen & 33.734 & 0.006 \\
Alkalinity & 1.593 & 0.002 \\
\hline
\end{tabular}

ification, and included temperature differentials and oxygen differentials. Both of these variables were higher in ponds prior to feeding. Temperature differential was positively correlated to solar radiation, and negatively related to wind velocity and mean weight of fish (multiple regression, $R^{2}$ $=0.673, P<0.001$ ). Oxygen differential was negatively correlated to feed application rate and positively correlated to solar radiation $\left(R^{2}=0.365, P<0.001\right)$. Wind velocity, feed input and mean fish weight all increased significantly during the experiment (correlation, $P<0.05$ ).

The economic analysis (Table 6) indicated that all of the treatments in this experiment would generate a profit, while first feeding at $100 \mathrm{~g}$ was most profitable. Inclusion of data from Diana et al. (1994) further clarified tilapia culture economics. Tilapia grown on fertilizer alone produced a reasonable profit, while feeding at full or 0.75 ad libitum was predicted to lose money. This loss of money occurred mainly because the fish were harvested at sizes less 
TABLE 5. Average values for physical and chemical parameters of pond water during the fertilized or fed stage as well as overall values. Most parameters in $\mathrm{mg} / \mathrm{L}$, except chlorophyll a $(\mu \mathrm{g} / \mathrm{L})$, gross primary productivity $\left(\mathrm{gO}_{2} / \mathrm{m}^{3}\right.$ per $\left.d\right)$, $\mathrm{pH}$, rainfall $(\mathrm{mm} / \mathrm{d})$, Secchi disk depth $(\mathrm{cm})$, solar radiation (Einsteins $/ \mathrm{m}^{2}$ per $\left.d\right)$ and temperature $(C)$.

\begin{tabular}{|c|c|c|c|c|c|c|}
\hline \multirow[b]{2}{*}{ Parameter } & \multicolumn{2}{|c|}{ Fertilization stage } & \multicolumn{2}{|c|}{ Fed stage } & \multicolumn{2}{|c|}{ Overall } \\
\hline & Mean & SD & Mean & SD & Mean & SD \\
\hline Alkalinity & 86.2 & 26.9 & 114.1 & 34.7 & 99.8 & 33.9 \\
\hline Chlorophyll $a$ & 172 & 142 & 415 & 265 & 291 & 243 \\
\hline DO & 2.45 & 1.76 & 2.47 & 1.52 & 2.46 & 1.64 \\
\hline DO differential & 12.6 & 4.6 & 7.3 & 4.4 & 10.0 & 5.2 \\
\hline Gross primary production & 19.2 & 6.1 & 20.2 & 7.1 & 19.7 & 6.6 \\
\hline Ammonia & 1.30 & 1.9 & 1.91 & 2.0 & 1.60 & 2.0 \\
\hline Orthophosphate & 0.24 & 0.18 & 0.09 & 0.15 & 0.17 & 0.18 \\
\hline $\mathrm{pH}$ & 8.01 & 0.59 & 7.54 & 0.32 & 7.78 & 0.53 \\
\hline Rainfall & 1.79 & 6.1 & 5.89 & 9.3 & 3.52 & 7.9 \\
\hline Secchi disk depth & 18.7 & 5.2 & 16.3 & 5.3 & 17.7 & 5.4 \\
\hline Solar radiation & 18.5 & 1.9 & 18.5 & 1.9 & 18.5 & 1.8 \\
\hline Temperature & 28.2 & 1.5 & 29.0 & 0.8 & 28.5 & 1.3 \\
\hline Temperature differential & 2.67 & 1.19 & 0.98 & 0.89 & 1.96 & 1.36 \\
\hline Dissolved inorganic nitrogen & 1.95 & 1.91 & 2.88 & 2.24 & 2.34 & 2.09 \\
\hline Total phosphorus & 0.55 & 0.22 & 0.54 & 0.18 & 0.54 & 0.20 \\
\hline Total suspended solids & 140.9 & 71.3 & 176.4 & 77.0 & 155.8 & 75.5 \\
\hline Total volatile solids & 43.9 & 131.2 & 58.4 & 34.7 & 51.1 & 96.1 \\
\hline
\end{tabular}

TABLE 6. Calculation of profit for each fertilization and feeding scheme in this experiment and in Diana et al. (1994). Fish were stocked at 3 per $m^{2}$. Profit is also extrapolated to annual since durations of experiments varied. The final three sets of numbers are extrapolated from Diana et al. (1994) to include dates when the fish reached $500 \mathrm{~g}$ in size.

\begin{tabular}{|c|c|c|c|c|c|c|c|}
\hline Treatment & $\begin{array}{l}\text { Fertilizer } \\
\text { (kg) }\end{array}$ & $\begin{array}{c}\text { Feed } \\
\text { (kg) }\end{array}$ & $\begin{array}{l}\text { Fish } \\
\text { biomass }\end{array}$ & $\begin{array}{c}\text { Fish } \\
\text { size }(g)\end{array}$ & Days & $\begin{array}{l}\text { Profit } \\
(\$)\end{array}$ & $\begin{array}{c}\text { Annual } \\
\text { profit } \\
(\$ / \text { ha per } y r)\end{array}$ \\
\hline \multicolumn{8}{|l|}{ Size at feeding } \\
\hline $50 \mathrm{~g}$ & 77.6 & 438 & 384.9 & 593 & 236 & 60.13 & $3,720.01$ \\
\hline $100 \mathrm{~g}$ & 77.6 & 358 & 384.3 & 596 & 236 & 99.65 & $6,164.89$ \\
\hline $150 \mathrm{~g}$ & 87 & 328 & 353.3 & 534 & 265 & 87.18 & $4,803.23$ \\
\hline $200 \mathrm{~g}$ & 101.1 & 398 & 340 & 627 & 305 & 37.54 & $1,796.88$ \\
\hline $250 \mathrm{~g}$ & 108.1 & 281 & 323.8 & 488 & 328 & 81.09 & $3,609.48$ \\
\hline \multicolumn{8}{|l|}{ Diana et al. (1994) } \\
\hline Fertilizer (F) only & 54.6 & 0 & 88.2 & 149 & 155 & 20.08 & $1,891.37$ \\
\hline Feed $(f)$ only & 0 & 347 & 249.2 & 416 & 155 & -30.73 & $-2,894.57$ \\
\hline $0.75 \mathrm{f} / 1 \mathrm{~F}$ & 52.3 & 284 & 268.1 & 403 & 155 & -2.74 & -258.39 \\
\hline $0.5 f / 1 F$ & 52.3 & 200 & 233.9 & 388 & 155 & 18.74 & $1,764.89$ \\
\hline $0.25 f / 1 F$ & 52.3 & 100 & 152.6 & 250 & 155 & 1.64 & 154.93 \\
\hline$f^{a}$ & 0 & 428 & 299 & 500 & 185 & 18.45 & $1,456.05$ \\
\hline $0.75 \mathrm{f}^{\mathrm{a}}$ & 64.2 & 357 & 333 & 500 & 190 & 62.92 & $4,834.69$ \\
\hline $0.5 \mathrm{f}^{\mathrm{a}}$ & 66.6 & 270.4 & 301 & 500 & 199 & 79.94 & $5,864.62$ \\
\hline
\end{tabular}

${ }^{a}$ Extrapolated linearly from feeding and growth rates in Diana et al. (1994). 
than $500 \mathrm{~g}$, when the value of fish $\mathbf{( \$ 0 . 6 0}$ per $\mathrm{kg}$ ) barely exceeded feed costs $(\$ 0.50$ per $\mathrm{kg}$ ). If the feeding and growth rates were extrapolated to continue linearly until the fish reached $500 \mathrm{~g}$, then all feeding treatments in Diana et al. (1994) would also be profitable, with feeding at 0.5 ad libitum most profitable. Overall, the most efficient system was first feeding (at $50 \%$ ad libitum) at $100 \mathrm{~g}$.

\section{Discussion}

The results of this experiment were much as expected, with a slower rate of growth in fertilized ponds than in fed ponds. Once ponds were fed, the growth rates of fish reached similar levels, regardless of time duration of prior fertilization. These results, along with earlier studies (Diana et al. 1994), indicate that CSC of tilapia in semiintensive ponds must occur during the first month of culture. If critical standing crop had not occurred prior to the first initiation of feeding in this study, then the first fed fish should have maintained the same growth rate for some time after feeding. Since each treatment increased dramatically in growth upon application of feed, CSC either does not exist for tilapia or had already occurred. While several studies have been conducted to evaluate CSC for tilapia, density-dependent growth of tilapia has been demonstrated both in fed (Zonneveld and Fadholi 1991) and fertilized systems (Diana et al. 1991a), but in both studies the differences in growth rate were expressed by the first month of culture. Green (1992) found that feed or fertilizer alone produced similar growth rates of tilapia during the first $30 \mathrm{~d}$. By day 60 , fish in the fertilizeralone treatment were significantly smaller than in feed-alone or combined fertilizerfeed treatments, indicating CSC in fertilizer-alone had been reached. Diana et al. (1994) found that higher growth occurred on feed than fertilizer alone, and higher rates of growth were measured by $30 \mathrm{~d}$. All of these studies vary in stocking density, pond types, and fish stocks so that direct comparisons are difficult, but the majority of evidence suggests early achievement of CSC by tilapia.

Supplemental feeding of fish resulted in much more rapid growth than fertilization alone, and the timing of supplemental feeding affected overall growth rate. The first two treatments, fed after 38 and $80 \mathrm{~d}$, respectively, ultimately resulted in the same size of tilapia at harvest. All subsequent feeding treatments required longer times to reach harvest size. Feed conversion rates averaged 1.03 for all treatments combined, and there were no significant differences among treatments in conversion efficiency. However, treatments fed earlier in the cycle had a larger portion of the fish growth occur under feeding regimes than under fertilization regimes, and reached harvest size sooner. The total amount of food applied did differ significantly among treatments (ANOVA), with treatment $E$ requiring the least feed, then $C$, then $B$ and $D$ (which were not significantly different), and $A$ requiring the most feed. In terms of overall efficiency including time, treatment B was most efficient and generated the largest profit. Thus, it appears from this analysis that supplementally feeding fish once they reached $100 \mathrm{~g}$ was the most effective means to reach larger size at limited costs.

The economic analysis of Nile tilapia ponds reflected the marginal profits for some systems in Thailand. While total costs (facilities, labor) were not included, some treatments were still predicted to lose money and others to profit only marginally. Semi-intensive production with urea and triple super phosphate was predicted to be reasonably profitable, which could possibly be improved by using less expensive organic fertilizers like chicken manure. Feeding would only realize its full potential if fish were grown to at least $500 \mathrm{~g}$ to achieve the highest market value. These analyses reflect common expectations for tilapia, which are most commonly grown for local consumption with limited market potential (Pillay 1993). Only large fish, with export markets 
and higher market values can be efficiently grown with feeds, and best at less than maximum feeding rates.

Growth of tilapia averaged $1.17 \mathrm{~g} / \mathrm{d}$ under optimal fertilization and $3.10 \mathrm{~g} / \mathrm{d}$ under fertilization and feeding. Both of these rates were comparable to or higher than growth in other studies (Zonneveld and Fadholi 1991; Green 1992; Diana et al. 1994). Feed application rates averaged $1.17 \% \mathrm{BW} / \mathrm{d}$, which is lower than maximum total consumption of pellets alone. Since growth was very high even at these low consumption rates, considerable consumption of natural foods must have also occurred. Diana et al. (1994) found similar growth rates and ad libitum consumption of supplemental feed by tilapia in ponds with both fertilizer and feed. Green (1992) combined fertilizer and feed $(1.5 \% \mathrm{BW} / \mathrm{d})$ in tilapia ponds in Honduras and increased growth but at a lower rate than recorded in this study $(2.03 \mathrm{~g} / \mathrm{d})$. Temperature differences between Honduras and Thailand may well explain this difference in growth. Combining feed and fertilizer resulted in rapid growth of tilapia at reduced food inputs compared to supplying feed alone (Diana et al. 1994).

Combined fertilizer and feed application resulted in efficient use of nutrients, since pond water quality did not vary significantly in any treatment before or after feed application at rates up to $390 \mathrm{~kg} / \mathrm{ha}$ per $\mathrm{d}$. Green (1992) found changes in primary production when fertilization and feeding were done. His feeding rates $(1.5 \% \mathrm{BW} / \mathrm{d}$, averaging up to $60 \mathrm{~kg} / \mathrm{ha}$ per d) may have resulted in overfeeding and nutrient accumulation, although his feed loading rates were lower than ours. Diana et al. (1994) found changes in water quality between feed only (averaging $100 \mathrm{~kg} / \mathrm{ha}$ per $\mathrm{d}$, maximum 190) and feed with fertilizer treatments (fed daily at up to $155 \mathrm{~kg} / \mathrm{ha}$ per d), but no differences between combined treatments (feed and fertilizer) and fertilizer alone. Apparently the efficient use of supplemental feed at a limited rate, along with fertilizer and natural feeds does not ad- versely affect water quality. From a pond management perspective, fertilization early in the grow-out, then adding supplemental feed once the fish reach $100-150 \mathrm{~g}$, is probably the optimal system to grow large tilapia efficiently.

\section{Acknowledgments}

This project was conducted with cooperation of the National Inland Fisheries Institute, Department of Fisheries, Ministry of Agriculture and Cooperatives, Thailand. Wattana Leelapatera aided in logistics and data evaluation. The study was conducted at the Ayutthaya Freshwater Fisheries Station, with assistance of the field crew. Data collection and lab analyses were done by V. Tansakul, S. Auworatham, W. Muthuwana, and assistants. B. Diana aided in data analysis and text preparation. This research is a component of the Pond Dynamics/Aquaculture CRSP supported by the Agency for International Development Grant No. DAN-4023-G-00-0031-00, and by contributions from participating institutions. This is contribution 1138 of the CRSP Aquaculture Project, and contribution 581 of the Center for Great Lakes and Aquatic Studies, University of Michigan.

\section{Literature Cited}

APHA (American Public Health Association). 1980. Standard methods for the examination of water and wastewater, fifteenth edition. Washington, D.C., USA.

Bolte, J., S. Nath and D. Ernst. 1996. Pond version 3.0. Department of Bioresource Engineering, Oregon State University, Corvallis, Oregon, USA.

Diana, J. S., D. D. Dettweiler and C. K. Lin. 1991 a. Effect of Nile tilapia (Oreochromis niloticus) on the ecosystem of aquaculture ponds, and its significance to the trophic cascade hypothesis. $\mathrm{Ca}$ nadian Journal of Fisheries and Aquatic Sciences 48:183-190.

Diana, J. S., C. K. Lin and P. J. Schneeberger. 1991b. Relationships among nutrient inputs, water nutrient concentrations, primary production, and yield of Oreochromis niloticus in ponds. Aquaculture 92:323-341.

Diana, J. S., C. K. Lin and K. Jaiyen. 1994. Supplemental feeding of tilapia in fertilized ponds. 
Journal of the World Aquaculture Society 25:497506.

Egna, H. S., N. Brown and M. Leslie. 1987. General reference: Site descriptions, material and methods for the global experiment. Pond dynamics/Aquaculture collaborative research data reports, volume 1. Oregon State University, Corvallis, Oregon, USA.

Green, B. W. 1992. Substitution of organic manure for pelleted feed in tilapia production. Aquaculture 101:213-222.

Hall, C. A. S. and R. Moll. 1975. Methods of assessing aquatic primary productivity. Pages 1953 in $\mathrm{H}$. Leith and R. H. Whittaker, editors. Primary productivity of the biosphere. Springer-Verlag, New York, USA.

Hepher, B. 1978. Ecological aspects of warm-water fish pond management. Pages 447-468 in S. D.
Gerking, editor. Ecology of fish production. John Wiley and Sons, New York, USA.

Knud-Hansen, C. F., C. D. McNabb and T. R. Batterson. 1991. Application of limnology for efficient nutrient utilization in tropical pond aquaculture. Proceedings of the International Association of Theoretical and Applied Limnologists 24: 2,541-2,543.

Piedrahita, R. H. 1988. Introduction to computer modeling of aquaculture pond ecosystems. Aquaculture and Fisheries Management 19:1-12.

Pillay, T. V. R. 1993. Aquaculture: Principles and practices. Blackwell Scientific Publishers, Oxford, England.

Wilkinson, L. 1990. SYSTAT: The system for statistics. SYSTAT, Inc., Evanston, Illinois, USA.

Zonneveld, N. and R. Fadholi. 1991. Feed intake and growth of red tilapia at different stocking densities in ponds in Indonesia. Aquaculture 99:83-94. 